\title{
REVIEW OF OCR TECHNIQUES USED IN AUTOMATIC MAIL SORTING OF POSTAL ENVELOPES
}

\author{
Dr.R.Radha and R.R.Aparna \\ Research Department of Computer science, SDNB Vaishnav College, \\ Affiliated to Madras University, Chennai, India.
}

\begin{abstract}
This paper presents a review of various OCR techniques used in the automatic mail sorting process. A complete description on various existing methods for address block extraction and digit recognition that were used in the literature is discussed. The objective of this study is to provide a complete overview about the methods and techniques used by many researchers for automating the mail sorting process in postal service in various countries. The significance of Zip code or Pincode recognition is discussed.
\end{abstract}

\section{KEYWORDS}

Neural Network, OCR, Pincode, Zipcode, Segmentation, Recognition, Address Block, Feature Extraction, Back propagation.

\section{INTRODUCTION}

The mechanization of mail sorting started in the year 1920. The first sorting machine was put into operation in the year 1950. From 1982 onwards developments were made in Optical Character Reader (OCR) which reads the mail piece destination address and Pincode and prints a Barcode for further sorting. This study would guide the researchers with existing methods in developing new OCR software to automate the mail sorting process in developing countries at a lesser cost.

To automate the sorting process initially the destination address block (DAB) has to be segmented from the envelope image, then the Zip code has to be located. The extracted Zip code is segmented into individual digits and recognition is performed. After recognition a relevant bar code pertaining the destination address is printed (Figure 1). This paper discusses the various methods used by many researches in the literature for performing DAB segmentation and character recognition. Section 2 gives the descriptions of various methods used for DAB segmentation. Section 3 discusses the various techniques used for Zip code recognition. Section 4 gives the performance comparison of different approaches proposed by different researchers in the literature. In Section 5 conclusion and future work is discussed.

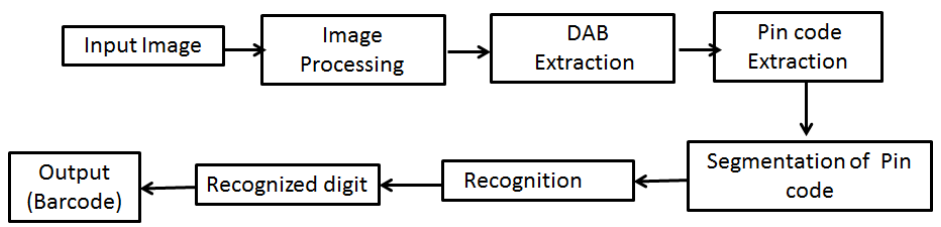

Figure 1: Procedure for Automatic mail sorting 
Signal \& Image Processing : An International Journal (SIPIJ) Vol.4, No.5, October 2013

\section{REVIEW OF VARIOUS METHODS USED FOR DAB SEGMENTATION}

Menoti et al. [23] have developed a DAB Segmentation algorithm based on feature selection in wavelet space. Experiments were performed on Brazilian postal envelopes. The images were decomposed into wavelet space using Mallat decomposition with Haar basis to identify the salient points. The four features based on low (L) and high (H) frequency (LL, LH, HL, HH) were obtained. 440 images with different layout and backgrounds were used. 85\% accuracy was achieved.

Wolf and Platt [40] have used Convolutional locator networks (CLN) to perform address block location on machine printed mail pieces that belongs to the US postal service(USPS). Varied shapes,sizes and justifications of DAB were considered. Instead of obtaining low level features high level abstract features of an address block (AB) was obtained using CLN.CLN detects the corners of AB.Explicit rules or models for extracting DAB was not used. The obtained features were converted to object hypothesis. The output of CLN gives a four feature map each representing a corner. Based on the intensity of the pixel in the feature map the corners were located. CLN was constructed with 3 layers, using back propagation algorithm. Feature maps of CLN were converted into address block location (ABL) candidates. 500 images were tested. 98.2\% accuracy was obtained.

Legal-Ayala and Facon [17] have used a learning based approach for postal envelope address block segmentation. Many features like pixel gray level values, mean, variance, skew and kurtosis were considered. Learning followed by segmentation was performed. 200 samples of Brazilian postal envelopes were taken. 10 samples were randomly chosen and submitted for learning stage. The 10 sample images and their ideal images (expected output images) were compared. The learning process computes all features of every pixel in both the images. The features were extracted from each pair of pixels that belongs to both the images along their neighbourhood. These extracted features were stored in the classification array. The other images were tested and DAB was segmented based on the stored classification array by using the K-Nearest Neighbour (KNN) and Euclidean distance measure. 98.6\% accuracy was achieved.

Gaceb et al. [8] have implemented a robust approach of address block localization in business mail by graph colouring technique. Graph colouring was performed to automatically separate the elements into homogeneous groups. Training was performed using b-colouring technique. $\mathrm{AB}$ was located using hierarchical graph colouring (HGC) and pyramidal data organization. The colouring was performed by applying different colour to the adjacent nodes in the graph. If a vertex is surrounded by all the specified number of colours then that node was referred as dominant node. Training was performed based on this b-colouring. This technique separates the dominant node that ensures a great inter class disparity. HGC was followed as it largely makes use of all the levels of pyramidal structure to group the objects of same nature. $98 \%$ accuracy on 750 samples was obtained.

Eiterer et al. [5] have performed postal envelope address block location by fractal based approach. Samples were taken from Brazilian post office. The fractal dimension of each pixel of postal envelope was computed using $2 \mathrm{D}$ variation. The fractal dimensions technique measures the roughness of a surface. Clustering was performed by K-means algorithm. After computing the fractal dimension for each image pixel, the resulting fractal image was then clustered by K-means into three clusters as background, post mark and stamp. The $2 \mathrm{D}$ variation procedure for these three clusters of neighbour window size were chosen as ( $r=3,5, r=3,5,7, r=3,5,7,9) .200$ postal envelopes were taken. They obtained an accuracy of $97 \%$ for segmenting $\mathrm{AB}, 66 \%$ for stamp and $92 \%$ for post mark by considering a region box of size $r=3,5,7,9$. 
Signal \& Image Processing : An International Journal (SIPIJ) Vol.4, No.5, October 2013

Yu et al. [43] have developed an algorithm based on heuristics for identifying the address written on light coloured background on an embossed label in the specified window of the envelope. The bottom up approach was used to build a pyramid model. Modified Ostu's method and connected component analysis (CCA) were used and by applying some heuristics the DAB was located. 109 samples (53 IBM magazine envelopes and 56 other envelopes) were taken. $72 \%$ and $93 \%$ accuracy was obtained.

Akira Yonekura and Facon [1] have used 2D histogram and morphological clustering based on Watershed transform to segment the DAB. Digitized image and its filtered version were taken. 2D histogram contains some statistical information about the gray values of the pixel at the same location in both the images. The morphological gray scale dual reconstruction preserves the peaks and valleys. The envelope image was segmented into 3 classes background, stamps and address blocks. 300 Brazil postal envelopes having complex background were taken as samples and the accuracy for background, stamp and $\mathrm{AB}$ was $90 \%, 25 \%$ and $75 \%$ respectively.

Facon et al. [6] have proposed an approach based on lacunarity to locate the AB in Brazil postal envelopes. Lacunarity depends on mean and variance for the window size throughout the images. It is a multi-scale measure describing the distribution of gaps within the texture. Region growing technique was applied to reconstruct the semantic objects like stamps, postmarks and address blocks. The features were extracted using lacunarity and normalized using non-linear transform. Threshold was applied to identify the objects. 200 samples were used and 93.5\% accuracy was achieved.

Xue et al. [41] have presented a new method to locate and interpret the DAB on handwritten Chinese envelopes. The features were extracted using geometric features, positional information, area and number of components. A new bottom up method was used to locate the DAB. It first extracts the connected component (CC) and then classifies them into text blocks and non-text blocks based on the obtained features. The segmented text blocks were merged to obtain the address block. $80 \%$ accuracy was achieved.

Idrissi [14] has used ensemble clustering techniques for address block segmentation. Cluster ensemble attempts to find more accurate and robust clustering results by combining the clustering results of a single or multiple clustering algorithms. The samples were segmented using single clustering algorithm and some features were extracted. The ensemble algorithm was developed by using the base clusters or many single clustering algorithms and then the clusters were combined. The graphics were removed from the image by using heuristics and by setting threshold. Single clustering algorithms like expected maximization (EM), single linkage, complete linkage were used. The cluster with the highest confidence score was segmented. The software was developed for the user to choose the appropriate clustering algorithm or combined algorithm. The accuracy of the algorithm can be tested by supplying different features for same algorithm or random data. 2000 samples form USPS and 1600 parcel images from Dutch sorting centre was used. Best results were obtained. It was proved that ensemble technique improved the accuracy of clustering process but resulted in increasing the computational time.

Govindaraju and Tulyakov [10] have performed DAB location by contour clustering based on heuristics. The CC was clustered based on the extracted features and contours. They achieved success by using agglomerative type clustering algorithms. The algorithm was similar to minimum spanning tree. Threshold setting was used and ranking was performed to classify the clusters on DAB. 1684 images from CEDAR data base were used. 1/3rd of it was tested and the DAB was correctly located on 272 images. They noted 50\% of accuracy and an increased performance. 
Signal \& Image Processing : An International Journal (SIPIJ) Vol.4, No.5, October 2013

Wang [39] has located the DAB on images of complex mail pieces, based on the size and the pixel density feature (PDF) of bounding box (BB) and heuristics. If the size is less than $10 \times 10$ pixels or greater than $100 \times 100$ pixels then those objects were removed considering them to be noise or graphics. By using positional information and region growing the DAB was segmented. 100 Chinese test image envelopes were used.90.7\% accuracy was achieved.

Bochnia and Facon [3] have performed address block extraction of magazine envelopes by applying multiple thresholds. Address was written on a label on the envelope. Each image was applied with threshold values that were modified from Pun, Johnnsen, Bille and Li algorithms. The final segmentation was obtained from the highest threshold. 70 images of News Paper envelopes having complex background were used and 80\% accuracy was achieved.

\section{REVIEW OF METHODS USED FOR DIGIT RECOGNITION}

Gao and Jin [9] have developed a vision based fast postal envelope identification system for isolated machine printed Chinese postal envelopes. Since the envelopes were of predefined sizes, the DAB was located by setting a threshold value. Address Line were segmented into sub segments using projection profile (PP). The segmentation path network was constructed in these sub segments and the best segmentation point was scored by the classifier. Feature extraction was performed by using 2D Gabor feature and gradient feature on binary and gray scale images. 256 dimensions Gabor feature and 516 dimension gradient features were used for recognition. Classification was performed using Euclidean distance. Linear discriminative analysis (LDA) was used for reducing the feature dimension. The Gabor bin obtained $98.92 \%$ for post code with a font size no lesser than 10.5. The experiments were performed on 761 mail images which contain 25060 characters. Average of 32.9 characters in 81 milliseconds has achieved a recognition accuracy of $98.7 \%$. Accuracy was highly dependent on font size.

Pal et al. [25] have experimented with Indian postal letters to segment the DAB and recognize the Pin code. Vertical and horizontal smoothing was performed using Run length smoothing algorithm (RLSA) to decompose the image into blocks. Based on pixel intensity, the text block (DAB) and non-text block (stamp, seal) were identified. Using positional information the DAB was segmented. The Pincode was localized by CCA assuming the number of digits in the pin code and based on some length and width measurements. The extracted pin code digits were normalized using aspect ratio adaptive normalization (ARAN). The numerals were recognized using two stage Multi-Layer Perceptron (MLP) classifier. The handwritten address contains Bangla and Arabic numerals. Back propagation (BP) algorithm was used. The input layer contains 784 neurons, output layer contains 16 neurons and hidden layer contains 400 neurons. The experiments were conducted on 2860 postal images, accuracy for DAB segmentation was 98.55\%, Pincode box recognition was 97.64\%. Recognition of 15096 numerals samples were taken, 8690 were used for training (Bangla and Arabic) and 6406 was used for testing. Bangla digit recognition accuracy was $94.13 \%$ and Arabic numeral recognition accuracy $93.00 \%$.

Roy et al. [28] have proposed a recognition method for recognizing the 6 digit Indian handwritten pin code in the DAB of postal documents that were written in English, Bangla and Hindi (Multiscript). The DAB was extracted using the method proposed by [25]. From the extracted DAB, the pin code was detected using positional information and segmented using Water Reservoir method. To the segmented numerals Modified quadratic discriminant function (MQDF) was applied. They used two feature set as proposed by [15]. Recognition was performed using dynamic programming. 16300 pin code samples were taken which contains 2692 Bangla, 8184 English, 5424 Devanagri. 94.14\% of recognition accuracy was obtained. 
Signal \& Image Processing : An International Journal (SIPIJ) Vol.4, No.5, October 2013

Sinha [31] has introduced a scheme for locating and recognizing words based on over segmentation followed by dynamic programming. The USPS postal samples containing cursive script postal address were used. ABL was performed by differentiating the foreground and background details by using Hidden Markov Model (HMM) based technique for ZIP location. But it was performed with minimum confidence. Hence recognition was performed. Zip code location and recognition were performed using shortest path problems. Three MLP classifiers with BP algorithm were used. The general classifier $(G)$ was constructed with 108 units in input layer, 120 units in the hidden layer and the output layer comprises 43 units. The digit classifier (D) contains 108 units in the input layer, 50 units in the Hidden layer and 11 units in the output layer. The alphabet classifier (A) contains 108 units in the input layer, 80 units in the hidden layer and 27 units in the output layer. 562 images were tested. 98\% accuracy was obtained for Zip code location and 95\% accuracy for Zip code recognition was obtained.

Ibrahim [12] has applied domain knowledge to the recognition of Zip code. He has developed the system by understanding the structure of Zip code by recognizing the first digit. It involves 2 stages, segmentation followed by recognition. He has constructed 26 MLP networks. Initially 9 MLP networks were constructed for digit (0-9) that identifies the state. Then based on the metaclass (second digit and other combinations), other 17 MLP networks were designed. 66214 digit samples were taken. 16000 was used for training and tested with 435 digits that belonged to CEDAR CDROM-1.His model relies on the prior knowledge of destination state. $88.76 \%$ accuracy was achieved.

Kimura et al. [15] have performed handwritten Zip code recognition using Lexicon free word recognition algorithm. Address block samples were taken form USPS database. The Zip Codes were extracted manually. Local Chain Code histogram for character contour was used as feature vector. The BB of each digit in the Zip code was divided into 7 X 7 blocks. In each block the Chain code histogram was calculated by using 4 directions. The size was down sampled to 4 X 4 blocks using Gaussian filters and 64 dimensions were obtained. The same way 400 dimensions were obtained by 9 X9 blocks by using 16 directions.5590 samples were taken and they obtained an accuracy of $99.2 \%$.The same method was applied by [3] but for Indian postal envelope containing English, Bangla and Hindi characters.

Le Cun et al. [16] have used Multilayer networks for performing handwritten Zip code recognition. BP was used to recognize digits. USPS samples were used. The images were normalized using linear transformations. 9298 segmented numerals were taken, 7291 handwritten digits and 2549 printed digits were used for training.2007 handwritten digits and 7000 printed digits were tested using MLP which contains 4 hidden layers. After 30 training phases accuracy of $97 \%$ was obtained with $3 \%$ rejection rate.

Vajda et al. [36] have proposed a new method for automatic recognition of Bangla and English numeral. Non-symmetric half plane (NSHP-HMM) was used for digit recognition. DAB was extracted using the method of [3].MLP with BP was used. The input layer contains 784 units, hidden layer contains 400 units and 16 units in the output layer. Three classifiers were proposed. The first classifier (C1) contains 16-class (Bangla and English numerals) tries to classify the digit, if the digit was recognized then it further recognizes using 10 class English classifier (C2) else it uses the 10 class Bangla classifier (C3).7500 Indian postal images were taken. 8690 digits were used for training which contains (4690 Bangla, 4000 English) and tested with 6406 digits (3179 Bangla and 3227 English).The accuracy achieved for 16-class classifier, Bangla classifier and English classifier was $92 \%, 94 \%$ and $93 \%$.

Velu and Vivekanandan.P [37] have provided a new method for automatic letter sorting for Indian postal address recognition system based on Pincode. DAB was cropped manually. Recognition of pin codes was performed using CC approach and ANN. The six nearest neighbour 
Signal \& Image Processing : An International Journal (SIPIJ) Vol.4, No.5, October 2013

$\mathrm{CC}$ technique was used. The ANN classifier (MLP-CPN) technique was used to recognize the numerals in the PIN code. ANN was constructed with 64 units in input layer, 100 units in hidden layer and 52 units in output layer. 6000 samples were used. The experiments were performed on automatic postal letter sorting machine in AMPS, Chennai. $99.5 \%$ of recognition accuracy was achieved.

$\mathrm{Lu}$ et al. [19] have discussed the applications of pattern recognition techniques for postal automation in China. The analysis was performed on the Siemens sorting machine. The DAB was extracted using connected component labelling by using Run based algorithm. Features like mean, standard deviation of merged $\mathrm{CC}$, area, aspect ratio and Euclidean distance. By analysing the obtained features noise, graphics and characters were classified and by using clustering algorithm the segments were combined to obtain the $\mathrm{AB}$. The normalized images of the isolated digits were sent to the classifiers. MLP using BP was performed. Chain Code histograms features were obtained by dividing the image in $4 \times 6$ grids and by considering 4 direction 96 features were obtained. Gray scale features were obtained by applying average filters by constructing $8 \times 12$ grids (96), thus 192 features were sent as input and 30 units in the hidden layer and 10 units in the output layer. Many classifiers like Tree classifiers based on topological features (TCTF), Havlet and threshold modified Bayesian classifier, Support Vector Machine (SVM) were used and the result were combined and was chosen based on higher confidence by voting algorithm.

Pfister et al. [27] have developed an OCR-GSA recognition system for handwritten Zip codes in a real world non- standard letter sorting system. OCR image processing algorithms were used to read destination address from postal envelopes by Siemens postal automation by Dutch post. Two classifiers were used to recognize the printed digits. Time delayed neural network (TDNN) was used to classify the scaled digits feature. While scanning the image the pixels of the image were grouped in squares called square pixels along with some extracted spatial frequency features. These were classified using small networks. After calculating the features the square pixels were clustered and by using some heuristics the address block was located. Zip code was located based on geometric features like aspect ratio. The TDNN scans the horizontal and vertical pixels using a pre-set window. NIST data base was used 120000 were trained. And tested on separate set of images using TDNN.99\% accuracy was achieved. The second classifier uses the structural and quantitative features from the digits pixel. Vectorization was performed by using skeletonization method. 97\% was achieved. When both the classifiers were combined $99 \%$ accuracy was achieved.

Alginaih and Siddiqi [2] have discussed about the multi-stage hybrid Arabic/Indian numeral OCR system. Three features F1, F2 and F3 were extracted and classified using three classifiers C1, C2 and C3. The first feature F1 was extracted from binary image (array of all pixels), F2 extracted using zoning technique, by which an array consisting of black pixels were obtained using square window. F3 was a maximized Fuzzy descriptive feature. The 3 classifiers were C1-Euclidean distance, C2-Hamming network, C3-Fuzzy neural network. Initially F1 serves as the input for C1 and $\mathrm{F} 2$ for $\mathrm{C} 2$ and $\mathrm{F} 3$ for $\mathrm{C} 3$. The output of $\mathrm{C} 1$ and $\mathrm{C} 2$ were compared if similar then accepted else again passes through $\mathrm{C} 3$.The outputs of $\mathrm{C} 3$ is compared with $\mathrm{C} 1$ and $\mathrm{C} 2$ if matches if any one classifier then accepted else rejected.400 images were trained and 20 tested. $99.4 \%$ accuracy was achieved.

Hull et al. [11] have proposed a black board based approach for recognition of handwritten Zip code. Zip code was located using positional information. Three features and three algorithms were used for classification. The template matching was performed by obtaining the features from the overall holistic characteristics of the image. A mixed statistical and structural classifier uses the features from the contours of the digit. Structural classifier uses the information about the size and displacement of strokes in image. USPS machine printed Zip codes were taken. 1754 digits 
were trained and 8129 were tested. The combined classifier performance was tested on 8000 digits and an accuracy of $91 \%$ was obtained.

Thomas [35] has developed an automated mail sorter system using SVM classifier. The features were extracted using $\mathrm{Hu}$ moments and SVM classifier was used for recognition. RLSA was used for image segmentation. The CC analysis was performed based on some features to classify the text and non-text zones. By using PP histograms were constructed based on the height, width and density of pixels to locate the Pin code. SVM was used for recognition and $99 \%$ accuracy was obtained. Only isolated Pincode digits were used.

Pervez and Suen [26] have proposed a recognition technique for totally unconstrained handwritten Zip codes. Recognition methods like statistical and structural methods were used. The classification module consists of two methods, prediction module which uses the statistical features and the structural module which uses the structural feature. Prediction module was performed based on Euclidean distance.5000 digits were trained and 3540 was tested. USPS database was used. 95\% accuracy was achieved. Structural module was computed using Fuzzy membership. It was trained using 1656 digits and tested using $1103.99 \%$ accuracy was achieved. When the classifiers were combined and tested the accuracy rose to $96 \%$.

Morshed et al. [24] have performed automatic sorting of mails by recognizing handwritten postal codes using neural network. DAB and Pincode were located using Heuristics. The neural network (NN) contains 144 units in input layer, 100 units in the hidden layer and 10 units in the output layer. 10400 segmented samples from Bangladesh Postal service were used. 5500 samples were trained and 4900 was tested. $92 \%$ accuracy was achieved.

Lu et al. [18] have implemented cost sensitive NN classifiers for post code recognition. MLP with BP was used. Unequal misclassification costs of all classes were the foundation of cost sensitive learning. Cost sensitive learning for BP algorithm was used and the following four methods were experimented cost sampling, cost convergence, rate adapting and threshold moving. 10702 postcode images were taken from Shanghai postal sorting centre. 5351 samples were used for training and 10702 were tested.81\% accuracy was achieved. Their technique can be adapted for recognition issue of post codes with alphabets or application that have class imbalance problem.

Wang [39] has proposed a recognition system for handwritten Bangla numeral for postal automation. Principal component analysis (PCA) was used based on image reconstruction, recognition and direction feature extraction were combined with PCA and SVM was used for classification. 16000 samples were taken from Bangladesh post. 6000 samples were trained and 10000 samples were tested and $95 \%$ accuracy was achieved.

Yonh and et al [42] have presented a new method for recognizing handwritten pin code using Fuzzy ARTMAP neural network for automatic mail sorting. A special image processing software WiT was used. Malaysian postal code (five digits) was written on various coloured envelopes post code box were taken as samples. Region of Interest (ROI) was used to locate the postcode box. They achieved a recognition accuracy of $90 \%$.

Siva and Uma [32] have proposed a new method to normalize the size of the Zip code image. Pixel scanning technique was implemented for segmentation and feature extraction of the image. ANN was used for classification. They achieved $99 \%$ accuracy.

Stuti and et al [34] have performed multi script numeral recognition using neural network. Experiments were performed on five different samples of handwritten Zip codes. They have experimented with double hidden layer that resulted in $96.53 \%$ accuracy. The input layer 
Signal \& Image Processing : An International Journal (SIPIJ) Vol.4, No.5, October 2013

constitutes of 150 neurons. The two hidden layers constitute of 250 neurons each and the output layer is composed of 16 neurons.

Matan et al. [22] have developed a Zip code recognition system for reading handwritten digits. The main feature of their neural network was that, the input was a pixel image rather than manually designed feature vectors. Recognition based segmentation was performed. The segmentation was a hybrid of connected component analysis, vertical cuts and neural network recognition. Segmentation cuts were performed based on the priori and CCA. The projection score was used for segmentation based recognition. USPS data base was used. The system was trained and tested on 10000 images. The accuracy obtained was $87 \%$.

Saifullah and Manry [29] have performed classification based segmentation of Zip codes. A character classifier was used to determine the trial segmentation that was most likely to be correct. After segmentation Discrete Fourier Transform (DFT) features were taken. 16 low frequency DFT features from each segmented character were used. Manual Zip block segmentation was performed. The segmentation line was chosen based on local maxima and minima (dips). Many trial dips were performed and based on heuristics the appropriate segmentation path was chosen.500 Zip codes from USPS database were used. 78 touching Zip codes using Bayes Gaussian classifier were recognized and the accuracy obtained was $76 \%$.

Wang et al. [38] have used localized arc pattern method for Zip code recognition. Two types of localized arc patterns, arc $(5,16)$ and arc $(67,9)$ were chosen. The first index implies the number of model patterns and the second index indicates the number of sub areas where frequencies of the model patterns are counted. The performance of the system highly depends on the threshold value. 2500 images form the IPTP of Japan mail was used. 90\% accuracy was obtained.

Strathy and Suen [33] have proposed a new system for reading handwritten Zip codes. Segmentation was performed using digit splitter by scanning from left to right in the Zip code block. The leftmost digit is recognized first and based on that other digits were extracted and recognized. Digit recognizer uses there NN. Features were extracted using pixel distance feature method (PDF).BP was used. The networks A, B, and C were constructed based on the following input, hidden and output units. A and B $(336,70,10), \mathrm{C}(288,80,10)$. The majority vote combination of $97 \%$ was obtained for 2711 images of USPS database.

Lucia Flores [20] has presented a recognition algorithm for printed or handwritten digits of the Zip code (RAPHZC).The segmentation was performed by scanning the entire digit and copying all the pixel values into a matrix. The connected digit was segmented based on the quantity of upper and lower horizontal lines found in the matrix and by using cross points. Four recognition functions were developed using heuristics. In each of these functions the final matrix was scanned and by using the crossing points and quantity of pixels the recognition was performed. 22400 handwritten digits and 15120 printed digits were taken from the Brazil correspondences. $99.99 \%$ accuracy was obtained.

Bouchaffra et al. [4] have used non-stationary Markovian models for performing Zip code recognition. Recognition scores combined with the domain knowledge obtained from the postal directory files. This data was fed into the model as n-gram statistics that are integrated with recognition scores of digit images. Gradient structural concavity recognizer was used to recognize isolated digits. The best model for Zip recognition was chosen based on the experiments that performed tests on all the possible models in terms of degrees of Markovain process. Their method merges the images and context in fully Bayesian framework. They obtained promising results. 20000 Zip codes from USPS database was used and 90\% accuracy was obtained. 
Signal \& Image Processing : An International Journal (SIPIJ) Vol.4, No.5, October 2013

Mahmoud [21] has performed recognition of digit using Gabor filters. Spatial Gabor filters with several scales and orientation were used to extract the Gabor features. CENPARM1 (Arabic Check database) was used. 7390 samples were used for training and 3035 samples were tested. $97 \%$ accuracy was obtained for one Nearest Neighbour classifier.

Idan and Chevalier [13] have performed recognition of handwritten digits based on Kohnen's self-organizing feature maps. The class labelling of neurons was performed on the map that emerges during the learning phase. The configuration of the map was set to $8 \times 8,8 \times 10$ and $11 \mathrm{x}$ 11 and a higher accuracy was $76 \%$ was obtained for $11 \times 11$ topological map. 1000 hand written Zip code digits were used. 735 digits were trained and 265 was tested.

Fujisawa et al. [7] have developed handwritten numeral recognition using gradient and curvature of gray scale image. Three procedures have been implemented based on the curvature coefficient, bi-quadratic interpolation and gradient vector interpolation was performed for calculating the curvature of the gray scale curves of an input image. The feature vectors were obtained using Bayesian approach. Discriminant function was used for classification.12000 images were taken from IPTP CDROM1 of Japan mail was used. The recognition accuracy for procedures A, B, C was $99.3 \%, 99.3 \%$ and $99.4 \%$ respectively. The samples were taken from Japanese New year greeting card.

Scofield et al. [30] have proposed a multiple neural network architecture (MNNS) or character recognition. Multiple network architecture was used to combine the response. Low level features were extracted from local edges, measures of raw pixels image and the image medial axis on the character contour. NIST database was used.25000 samples were used for training and 4767 was tested. Four network (MNNS) were constructed and arranged in Hierarchical manner. Restricted coulomb energy (RCE) was used in 3 layers of feed forward architecture. Cells in the second layer are radius limited perceptrons referred as Radial Bias function (RBF) used as computer activation function. Two BP was constructed in the first level and two RCE using RBF was constructed in the second level. 7300 samples were trained and 2000 samples were tested. The combined performance was $90 \%$.

\section{PERformanCE COMPARISON}

The following tables display the performance comparison results of all the above mentioned methods used in the literature. (Table 1) displays the performance comparison of DAB segmentation. (Table 2) displays the comparison analysis of recognition of Zip code digits using MLP-BP technique. (Table 3) displays the comparison analysis of recognition of Zip code digits using other classifiers. The datasets were collected from various countries Postal Service (PS).

Table 1: Performance Analysis of DAB Segmentation

\begin{tabular}{|l|l|l|l|l|l|l|}
\hline $\begin{array}{l}\text { S. } \\
\text { No }\end{array}$ & Author & Year & Dataset & Method Used & $\begin{array}{l}\text { Test } \\
\text { Set }\end{array}$ & Accuracy \\
\hline 1 & $\begin{array}{l}\text { Gao and Jin } \\
{[9]}\end{array}$ & 2009 & China PS & $\begin{array}{l}\text { Geometric and positional } \\
\text { features }\end{array}$ & 761 & $98.7 \%$ \\
\hline 2 & $\begin{array}{l}\text { Gaceb et al. } \\
{[8]}\end{array}$ & 2009 & France PS & $\begin{array}{l}\text { Hierarchical Graph } \\
\text { colouring and Pyramidal } \\
\text { data organization }\end{array}$ & 750 & $98 \%$ \\
\hline 3 & Idrissi [14] & 2008 & USPS & $\begin{array}{l}\text { Cluster ensembling } \\
\text { Technique }\end{array}$ & 3600 & $\begin{array}{l}\text { Positive } \\
\text { results }\end{array}$ \\
\hline
\end{tabular}


Signal \& Image Processing : An International Journal (SIPIJ) Vol.4, No.5, October 2013

\begin{tabular}{|c|c|c|c|c|c|c|}
\hline 4 & $\begin{array}{l}\text { Facon et al. } \\
\text { [6] }\end{array}$ & 2005 & Brazil PS & $\begin{array}{l}\text { Lacunarity and Region } \\
\text { growing }\end{array}$ & 200 & $93.5 \%$ \\
\hline 5 & $\begin{array}{l}\text { Pal et al. } \\
{[25]}\end{array}$ & 2004 & Indian PS & $\begin{array}{l}\text { Run length encoding, } \\
\text { Geometric and Positional } \\
\text { features. }\end{array}$ & 2860 & $98.55 \%$ \\
\hline 6 & $\begin{array}{l}\text { Eiterer et al. } \\
\text { [5] }\end{array}$ & 2004 & Brazil PS & $\begin{array}{l}\text { Fractal approach, K- } \\
\text { means }\end{array}$ & 200 & $97 \%$ \\
\hline 7 & $\begin{array}{l}\text { Menoti et al. } \\
{[23]}\end{array}$ & 2003 & Brazil PS & Wavelet & 440 & $85 \%$ \\
\hline 8 & $\begin{array}{l}\text { Legal-Ayala } \\
\text { and Facon } \\
{[17]}\end{array}$ & 2003 & Brazil PS & $\begin{array}{l}\text { Learning based approach, } \\
\text { Geometric features, KNN } \\
\text { and Euclidean distance }\end{array}$ & 190 & $98.6 \%$ \\
\hline 9 & $\begin{array}{l}\text { Akira } \\
\text { Yonekura } \\
\text { and Facon } \\
{[1]}\end{array}$ & 2003 & Brazil PS & $\begin{array}{l}\text { 2D-histogram, } \\
\text { Morphological clustering } \\
\text { and Watershed transform }\end{array}$ & 300 & $75 \%$ \\
\hline 10 & $\begin{array}{l}\text { Govindaraju } \\
\text { and } \\
\text { Tulyakov } \\
{[10]}\end{array}$ & 2003 & $\begin{array}{l}\text { USPS } \\
\text { CEDAR }\end{array}$ & $\begin{array}{l}\text { Contour and } \\
\text { Agglomerative clustering }\end{array}$ & 561 & $50 \%$ \\
\hline 11 & $\begin{array}{l}\text { Xue et al. } \\
{[41]}\end{array}$ & 2001 & China PS & $\begin{array}{l}\text { Geometric, positional } \\
\text { features and Bottom up } \\
\text { analysis. }\end{array}$ & - & $80 \%$ \\
\hline 12 & Wang [39] & 2001 & China PS & $\begin{array}{l}\text { Pixel Density Feature, } \\
\text { Region growing. }\end{array}$ & 100 & $90.7 \%$ \\
\hline 13 & Sinha [31] & 1997 & USPS & $\begin{array}{l}\text { Geometric Features and } \\
\text { Hidden Markov Model }\end{array}$ & 562 & $98 \%$ \\
\hline 14 & Yu et al. [43] & 1997 & $\begin{array}{l}\text { IBM } \\
\text { envelopes }\end{array}$ & $\begin{array}{l}\text { Heuristics, bottom up and } \\
\text { pyramidal analysis. }\end{array}$ & 53 & $72 \%$ \\
\hline 15 & $\begin{array}{l}\text { Wolf and } \\
\text { Platt [40] }\end{array}$ & 1991 & USPS & $\begin{array}{l}\text { Convolution locator } \\
\text { network. }\end{array}$ & 500 & $98.2 \%$ \\
\hline 16 & $\begin{array}{l}\text { Bochnia and } \\
\text { Facon [3] }\end{array}$ & - & $\begin{array}{l}\text { Magazine } \\
\text { envelope }\end{array}$ & Modified Threshold & 70 & $80 \%$ \\
\hline
\end{tabular}

Table 2: Performance Analysis of Zip code Recognition using MLP-BP

\begin{tabular}{|l|l|l|l|l|l|l|l|l|}
\hline $\begin{array}{l}\text { S. } \\
\text { No }\end{array}$ & Author & Year & $\begin{array}{l}\text { Datas } \\
\text { et }\end{array}$ & $\begin{array}{l}\text { Feature } \\
\text { Extraction }\end{array}$ & $\begin{array}{l}\text { Recognition } \\
\text { Method }\end{array}$ & $\begin{array}{l}\text { Trai- } \\
\text { ned } \\
\text { set }\end{array}$ & $\begin{array}{l}\text { Test } \\
\text { Set }\end{array}$ & $\begin{array}{l}\text { Accura } \\
\text { cy }\end{array}$ \\
\hline 1 & $\begin{array}{l}\text { Siva and } \\
\text { Uma } \\
{[32]}\end{array}$ & 2012 & $\begin{array}{l}\text { India } \\
\text { PS }\end{array}$ & $\begin{array}{l}\text { Pixels from } \\
\text { normalized } \\
\text { digit }\end{array}$ & $\begin{array}{l}\text { (IP-225, HD- } \\
300, \text { OP-10) }\end{array}$ & 433 & 93 & $99 \%$ \\
\hline 2 & $\begin{array}{l}\text { Lu et al. } \\
{[18]}\end{array}$ & 2012 & $\begin{array}{l}\text { China } \\
\text { PS }\end{array}$ & $\begin{array}{l}\text { Pixels from } \\
\text { digit image }\end{array}$ & $\begin{array}{l}\text { Costsentive } \\
\text { BP }\end{array}$ & 5351 & 10702 & $81 \%$ \\
\hline 3 & $\begin{array}{l}\text { Stuti } \\
\text { and } \\
\text { et al } \\
{[34]}\end{array}$ & 2011 & $\begin{array}{l}\text { India } \\
\text { PS }\end{array}$ & Pixel scaning & $\begin{array}{l}\text { (IP-150, 2HD- } \\
250, \text { OP-16) }\end{array}$ & - & $\begin{array}{l}10 \text { set } \\
\text { of 5 } \\
\text { Scripts }\end{array}$ & $96.53 \%$ \\
\hline
\end{tabular}


Signal \& Image Processing : An International Journal (SIPIJ) Vol.4, No.5, October 2013

\begin{tabular}{|c|c|c|c|c|c|c|c|c|}
\hline 4 & $\begin{array}{l}\text { Velu } \\
\text { and } \\
\text { Vivekan } \\
\text { an- } \\
\text { dan.P } \\
{[37]} \\
\end{array}$ & 2010 & $\begin{array}{l}\text { India } \\
\text { PS }\end{array}$ & $\begin{array}{l}\text { Contour } \\
\text { features using } \\
\text { Chain code }\end{array}$ & $\begin{array}{l}\text { (IP-64, HD- } \\
100, \text { OP-52) }\end{array}$ & - & 6000 & $99.5 \%$ \\
\hline 5 & $\begin{array}{l}\text { Vajda et } \\
\text { al. } \\
{[36]}\end{array}$ & 2009 & $\begin{array}{l}\text { India } \\
\text { PS }\end{array}$ & $\begin{array}{l}\text { Normalized } \\
\text { raw image } \\
\text { pixels }\end{array}$ & $\begin{array}{l}\text { C1-(IP-784, } \\
\text { HD-400, OP- } \\
\text { 16), } \\
\text { C2-(IP-784, } \\
\text { HD-400, OP- } \\
\text { 10), } \\
\text { C3-(IP- } \\
\text { 784,HD- } \\
\text { 400,OP-10), } \\
\text { 3-networks } \\
\text { used. }\end{array}$ & 8690 & 6406 & $\begin{array}{l}\text { C1- } \\
92 \%, \\
\text { C2- } \\
94 \%, \\
\text { C3- } \\
93 \%\end{array}$ \\
\hline 6 & $\begin{array}{l}\text { Ibrahim } \\
\text { [12] }\end{array}$ & 2007 & $\begin{array}{l}\text { USPS } \\
\text { CEDA } \\
\mathrm{R}\end{array}$ & $\begin{array}{l}\text { Pixels from } \\
\text { the image }\end{array}$ & $\begin{array}{l}26 \text { network } \\
\text { were } \\
\text { Used }\end{array}$ & 16000 & 435 & $88.76 \%$ \\
\hline 7 & $\begin{array}{l}\text { Morshe } \\
\text { d } \\
\text { et al. } \\
{[24]} \\
\end{array}$ & 2007 & $\begin{array}{l}\text { Bangla } \\
\text { Desh } \\
\text { PS }\end{array}$ & $\begin{array}{l}\text { Pixel from } \\
\text { normalized } \\
\text { image }\end{array}$ & $\begin{array}{l}\text { (IP-144, HD- } \\
100, \text { OP-16) }\end{array}$ & 55000 & 4900 & $92 \%$ \\
\hline 8 & $\begin{array}{l}\text { Pal et al. } \\
{[25]}\end{array}$ & 2004 & $\begin{array}{l}\text { India } \\
\text { PS }\end{array}$ & $\begin{array}{l}\text { Raw image } \\
\text { Pixels }\end{array}$ & $\begin{array}{l}\text { (IP-784, HD- } \\
16, \text { OP-400) }\end{array}$ & 8690 & 6406 & $94 \%$ \\
\hline 9 & $\begin{array}{l}\text { Sinha } \\
{[31]}\end{array}$ & 1997 & USPS & $\begin{array}{l}\text { Contour and } \\
\text { cutting point } \\
\text { features }\end{array}$ & $\begin{array}{l}\text { G(IP-108, HD- } \\
\text { 120, OP-43) } \\
\text { D-(IP-108, } \\
\text { HD-50,OP-11) } \\
\text { A-(IP- } \\
\text { 108,HD- } \\
\text { 80,OP-27), } \\
\text { 3-networks } \\
\text { used }\end{array}$ & - & 562 & $95 \%$ \\
\hline 10 & $\begin{array}{l}\text { Strathy } \\
\text { and } \\
\text { Suen } \\
\text { [33] }\end{array}$ & 1995 & USPS & $\begin{array}{l}\text { Pixel distance } \\
\text { feature(PDF) }\end{array}$ & $\begin{array}{l}\text { (A,B)-(IP-336, } \\
\text { HD-70, OP- } \\
\text { 10),C-(IP-88, } \\
\text { HD-80, OP- } \\
\text { 10),3-networks }\end{array}$ & - & 2711 & $97 \%$ \\
\hline 11 & $\begin{array}{l}\text { Matan et } \\
\text { al. } \\
{[22]}\end{array}$ & 1992 & USPS & $\begin{array}{l}\text { Pixels from } \\
\text { Image }\end{array}$ & NN & 10000 & 10000 & $87 \%$ \\
\hline 12 & $\begin{array}{l}\text { Scofield } \\
\text { et al. } \\
{[30]}\end{array}$ & 1991 & NIST & $\begin{array}{l}\text { Low level } \\
\text { features (edge, } \\
\text { mean of } \\
\text { pixels, medial } \\
\text { axis) } \\
\end{array}$ & $\begin{array}{l}\text { 2-BP and 2- } \\
\text { REC based on } \\
\text { RBF, } \\
\text { 4-networks }\end{array}$ & 7300 & 2000 & $90 \%$ \\
\hline 13 & $\begin{array}{l}\text { Le Cun } \\
\text { et al. } \\
\text { [16] }\end{array}$ & 1990 & USPS & $\begin{array}{l}\text { Gray scale } \\
\text { features in } \\
\text { the range( }-1 \\
\text { to } 1) \\
\end{array}$ & $4 \mathrm{HD}$ & 9840 & 9007 & $97 \%$ \\
\hline
\end{tabular}

(MLP-Multi layer perceptron, BP-Back Propagation, IP-Input layer, HD-Hidden Layer, OPOutput Layer) 
Signal \& Image Processing : An International Journal (SIPIJ) Vol.4, No.5, October 2013

Table 3: Performance Analysis of Zip code Recognition using other Classifiers

\begin{tabular}{|c|c|c|c|c|c|c|c|c|}
\hline $\begin{array}{l}\text { S. } \\
\text { No }\end{array}$ & Author & Year & $\begin{array}{l}\text { Datas } \\
\text { et }\end{array}$ & $\begin{array}{l}\text { Feature } \\
\text { Extraction }\end{array}$ & $\begin{array}{l}\text { Recognition } \\
\text { Method }\end{array}$ & $\begin{array}{l}\text { Trai } \\
\text { ned } \\
\text { Set }\end{array}$ & $\begin{array}{l}\text { Test } \\
\text { Set }\end{array}$ & $\begin{array}{l}\text { Accur } \\
\text { acy }\end{array}$ \\
\hline 1 & $\begin{array}{l}\text { Thomas } \\
\text { [35] }\end{array}$ & 2011 & $\begin{array}{l}\text { India } \\
\text { PS }\end{array}$ & Hu moments & SVM & - & - & $99 \%$ \\
\hline 2 & $\begin{array}{l}\text { Alginaih } \\
\text { and } \\
\text { Siddiqi } \\
{[2]}\end{array}$ & 2010 & $\begin{array}{l}\text { Arabia } \\
\text { PS }\end{array}$ & $\begin{array}{l}\text { Array of } \\
\text { pixels, Zoning } \\
\text { features and } \\
\text { Fuzzy } \\
\text { membership }\end{array}$ & $\begin{array}{l}\text { Euclidean dis } \\
\text { tance, } \\
\text { Hamming } \\
\text { Network and } \\
\text { Fuzzy } \\
\text { classifier }\end{array}$ & 400 & 200 & $99.4 \%$ \\
\hline 3 & $\begin{array}{l}\text { Mahmoud } \\
{[21]}\end{array}$ & 2009 & $\begin{array}{l}\text { CENN } \\
\text { PRAM } \\
1\end{array}$ & Gabor features & $\begin{array}{l}\text { Gabor filters } \\
\text { and nearest } \\
\text { neighbour }\end{array}$ & 7390 & 3035 & $97 \%$ \\
\hline 4 & $\begin{array}{l}\text { Gao and } \\
\text { Jin [9] }\end{array}$ & 2009 & $\begin{array}{l}\text { China } \\
\text { PS }\end{array}$ & $\begin{array}{l}\text { 2D Gabor and } \\
\text { Gradient } \\
\text { features }\end{array}$ & $\begin{array}{l}\text { Euclidean } \\
\text { distance }\end{array}$ & - & 25060 & $98.7 \%$ \\
\hline 5 & $\begin{array}{l}\text { Pal et al. } \\
{[25]}\end{array}$ & 2009 & $\begin{array}{l}\text { India } \\
\text { PS }\end{array}$ & $\begin{array}{l}2 \text { feature set } \\
\text { referred by } \\
{[15]}\end{array}$ & $\begin{array}{l}\text { Dynamic } \\
\text { programming }\end{array}$ & - & 16300 & $\begin{array}{l}94.14 \\
\%\end{array}$ \\
\hline 6 & Wang[39] & 2001 & $\begin{array}{l}\text { Bangla } \\
\text { desh } \\
\text { PS }\end{array}$ & $\begin{array}{l}\text { PCA and } \\
\text { directional } \\
\text { feature }\end{array}$ & SVM & 6000 & 10000 & $95 \%$ \\
\hline 7 & $\begin{array}{l}\text { Pfister et } \\
\text { al. } \\
{[27]}\end{array}$ & 2000 & $\begin{array}{l}\text { Dutch } \\
\text { NIST }\end{array}$ & $\begin{array}{l}\text { Pseudo gray } \\
\text { values }\end{array}$ & $\begin{array}{l}\text { TDNN, } \\
\text { structural } \\
\text { and } \\
\text { quantitative } \\
\text { features }\end{array}$ & $\begin{array}{l}1200 \\
00\end{array}$ & - & $99 \%$ \\
\hline 8 & $\begin{array}{l}\text { Yonh and } \\
\text { et al [42] }\end{array}$ & 1999 & $\begin{array}{l}\text { Malay } \\
\text { sia PS }\end{array}$ & $\begin{array}{l}\text { Krisch algo- } \\
\text { rithm and } \\
\text { image com- } \\
\text { pression }\end{array}$ & $\begin{array}{l}\text { Fuzzy } \\
\text { ARTMAP }\end{array}$ & - & - & $90 \%$ \\
\hline 9 & $\begin{array}{l}\text { Bouchaffr } \\
\text { a } \\
\text { et al. [4] }\end{array}$ & 1999 & USPS & $\begin{array}{l}\text { Measures of } \\
\text { input pattern } \\
\text { of the digit } \\
\text { image }\end{array}$ & $\begin{array}{l}\text { Non- } \\
\text { stationary } \\
\text { Markovian } \\
\text { model, } \\
\text { contextual } \\
\text { knowledge } \\
\text { and } \\
\text { Bayesian } \\
\text { classifier }\end{array}$ & 6000 & 20000 & $90 \%$ \\
\hline
\end{tabular}


Signal \& Image Processing : An International Journal (SIPIJ) Vol.4, No.5, October 2013

\begin{tabular}{|c|c|c|c|c|c|c|c|c|}
\hline 10 & $\begin{array}{l}\text { Fujisawa } \\
\text { et al. [7] }\end{array}$ & 1999 & $\begin{array}{l}\text { IPTP } \\
\text { Japan }\end{array}$ & $\begin{array}{l}\text { Gradient } \\
\text { calculations } \\
\text { using } \\
\text { Roberts filter }\end{array}$ & $\begin{array}{l}\text { Discriminant } \\
\text { function, } \\
\text { Curvature co } \\
\text { efficient, Bi- } \\
\text { quadratic } \\
\text { interpolation } \\
\text { and } \\
\text { Gradient } \\
\text { vector inter- } \\
\text { Polation }\end{array}$ & - & 12000 & $\begin{array}{l}\text { A- } \\
99.3 \% \\
\text { B- } \\
99.3 \% \\
\text { C- } \\
99.4 \%\end{array}$ \\
\hline 11 & $\begin{array}{l}\text { Lucia } \\
\text { Flores } \\
\text { [20] }\end{array}$ & 1998 & $\begin{array}{l}\text { Brazil } \\
\text { PS }\end{array}$ & $\begin{array}{l}\text { Pixel distance } \\
\text { feature (PDF) }\end{array}$ & $\begin{array}{l}\text { Recognition } \\
\text { function } \\
\text { using } \\
\text { Heuristics }\end{array}$ & - & 37520 & $\begin{array}{l}99.99 \\
\%\end{array}$ \\
\hline 12 & $\begin{array}{l}\text { Kimura } \\
\text { et al. [15] }\end{array}$ & 1995 & USPS & $\begin{array}{l}\text { Two set } \\
\text { feature } \\
\text { using local } \\
\text { Chain code } \\
\text { histogram by } \\
\text { dividing the } \\
\text { image into } \\
\text { blocks. }\end{array}$ & $\begin{array}{l}\text { Dynamic } \\
\text { programming }\end{array}$ & - & 5590 & $99.2 \%$ \\
\hline 13 & $\begin{array}{l}\text { Saifullah } \\
\text { and } \\
\text { Manry } \\
\text { [29] }\end{array}$ & 1993 & USPS & $\begin{array}{l}16 \text { Low } \\
\text { frequency } \\
\text { features } \\
\text { using DFT }\end{array}$ & $\begin{array}{l}\text { Bayesian } \\
\text { classifier }\end{array}$ & - & 78 & $76 \%$ \\
\hline 14 & $\begin{array}{l}\text { Wang et } \\
\text { al. } \\
\text { [38] }\end{array}$ & 1999 & $\begin{array}{l}\text { IPTP } \\
\text { Japan }\end{array}$ & $\begin{array}{l}64 x 64, \text { Binary } \\
\text { pattern by } \\
\text { normalizing } \\
\text { location and } \\
\text { size }\end{array}$ & $\begin{array}{l}\text { Localized } \\
\text { Arc Patterns }\end{array}$ & - & 2500 & $90 \%$ \\
\hline 15 & $\begin{array}{l}\text { Idan and } \\
\text { Chevalier } \\
\text { [13] }\end{array}$ & 1991 & $\begin{array}{l}\text { France } \\
\text { PS }\end{array}$ & $\begin{array}{l}\text { Gaussian } \\
\text { filters, } \\
\text { directional } \\
\text { features and } \\
\text { PCA }\end{array}$ & $\begin{array}{l}\text { Kohenen's } \\
\text { self- } \\
\text { organizing } \\
\text { maps }\end{array}$ & - & 735 & $36 \%$ \\
\hline 16 & $\begin{array}{l}\text { Hull et al. } \\
\text { [11] }\end{array}$ & 1988 & USPS & $\begin{array}{l}\text { Pixels from } \\
\text { image, contour } \\
\text { features of the } \\
\text { digit, size and } \\
\text { displacement } \\
\text { of strokes in } \\
\text { images }\end{array}$ & $\begin{array}{l}\text { Template } \\
\text { matching, } \\
\text { Mixed } \\
\text { statistical } \\
\text { and } \\
\text { structural } \\
\text { classifier, } \\
\text { Structural } \\
\text { classifier }\end{array}$ & 1754 & 8000 & $91 \%$ \\
\hline 17 & $\begin{array}{l}\text { Pervez } \\
\text { and } \\
\text { Suen [26] }\end{array}$ & 1986 & USPS & $\begin{array}{l}\text { Statistical and } \\
\text { Structural }\end{array}$ & $\begin{array}{l}\text { Euclidean } \\
\text { distance and } \\
\text { Fuzzy } \\
\text { membership }\end{array}$ & 6656 & 46543 & $96 \%$ \\
\hline
\end{tabular}


Signal \& Image Processing : An International Journal (SIPIJ) Vol.4, No.5, October 2013

\section{CONCLUSION}

The proposed paper explained the various existing methods used in the OCR for automating the mail sorting process in the literature. It was noted that MLP-BP classifier was widely used for recognition. The future work mainly concentrates on developing a fast and cost effective algorithm for extraction of DAB and recognition Pin code for the business mail service of Indian post.

\section{REFERENCES}

[1] E. Akira Yonekura and J. Facon. (2003), “2-D histogram-based segmentation of postal envelopes", In Proceedings of 16th SIBGRAPI Brazilian Symposium on Computer Graphics and Image Processing, pp: 247-253.

[2] Yasser M. Alginaih and Abdul Ahad Siddiqi. (2010),"Multistage hybrid Arabic/Indian numeral OCR system”, International Journal of Computer Science and Information Security.

[3] Gerson Bochnia and Jacques Facon."Address block extraction of magazine envelopes by multiple threshold”. Rua Imaculada Conceic sao 1155, Prado Velho, 80215-901 Curitiba-Pr, Brazil.

[4] Djamel Bouchaffra, Sargur Srihari and Venu Govindaraju. (1999)."Postprocessing of recognized strings using nonstationary Markovian models". IEEE Transactions on Pattern Analysis and Machine Intelligence, Vol. 21, pp: 990-999.

[5] Luiz Felipe Eiterer, Jacques Facon, and David Menoti. (2004), "Postal envelope address block location by fractal-based approach”, In Proceedings of 17th Brazilian Symposium on Computer Graphics and Image Processing, pp: 90-97.

[6] Jacques Facon, David Menoti, and Arnaldo de Albuquerque Araujo. (2005), "Lacunarity as a texture measure for address block segmentation". In Proceedings of the 10th IberoAmerican Congress conference on Progress in Pattern Recognition, Image Analysis and Applications, pp: 112-119.

[7] Y. Fujisawa, Meng Shi, T.Wakabayashi, and F. Kimura. (1999), " Handwritten numeral recognition using gradient and curvature of gray scale image". In Proceedings of the 5th International Conference on Document Analysis and Recognition, ICDAR, pp: 277-280.

[8] Djamel Gaceb, Veronique Eglin, Frank Lebourgeois, and Hubert Emptoz. (2009), "Robust approach of address block localization in business mail by graph coloring", The International Arab Journal of Information Technology.

[9] Xue Gao and Lianwen Jin. (2009), "Swift post a vision-based fast postal envelope identification system”. In Proceedings of the 2009 IEEE International Conference on Systems, Man, and Cybernetics, pp: 3268-3273.

[10] Venu Govindaraju and Sergey Tulyakov. (2003), "Postal address block location by contour clustering". In Proceedings of the Seventh International Conference on Document Analysis and Recognition, Vol.1, pp: 429.

[11] Jonathan J. Hull, Sargur N. Srihari, Leonard Kuan, Peter Cullen, and Paul Palumbo. (1988), "A blackboard-based approach to handwritten Zip code recognition”. In Proceedings of 3rd United States Postal Service Advanced Technology Conj, pp:1018-1032.

[12] Chabaan Ibrahim. (2007), "Applying Domain Knowledge To The Recognition Of Handwritten Zip Codes". PhD thesis, Indiana University, South Bend, US.

[13] Y. Idan and R.C. Chevalier. (1991), "Handwritten digits recognition by a supervised Kohonen-like learning algorithm". In IEEE International Joint Conference on Neural Networks, Vol. 3, pp: 25762581.

[14] Mustafa Idrissi. (2008),“Address block segmentation using ensemble clustering techniques”, PhD thesis, Faculty of Electrical Engineering, Mathematics and Computer Science, Delft,

[15] F. Kimura, Y. Miyake, and M. Shridhar. (1995), "Handwritten Zip code recognition using lexicon free word recognition algorithm". In Proceedings of the 3rd International Conference on Document Analysis and Recognition, Vol. 2, pp: 906.

[16] Y. Le Cun, O. Matan, B. Boser, D. Denker, J.S. Henderson, W.Jacket, L.D.Baird, H.S. Howard, R.E. Hubbard. (1990), "Handwritten Zip code recognition with multilayer networks". In Proceedings of the 10th International Conference on Pattern Recognition. 
Signal \& Image Processing : An International Journal (SIPIJ) Vol.4, No.5, October 2013

[17] Horacio Andres Legal-Ayala and Jacques Facon. (2003), "Image segmentation by learning approach". In Proceedings of the 7th International Conference on Document Analysis and Recognition, Vol.2, pp: 819.

[18] Shujing Lu, Li Liu, Yue Lu, and Patrick S. P. Wang. (2012), “ Cost-sensitive neural network classifiers for postcode recognition”. International Journal of Pattern Recognition and Artificial Intelligence, Vol.26, No.5.

[19] Yue Lu, Xiao Tu, Shujing Lu, and Patrick S P Wang. (2010), “Application of pattern recognition technology to postal automation in china". Pattern Recognition and Machine Vision.

[20] E. Lucia Flores. (1998), "A recognition algorithm of printed or handwritten digits of the Zip code". In proceedings of Telecommunications Symposium, IEEE International, vol. 2, pp: 671-676.

[21] S.A. Mahmoud. (2009), “ Recognition of Arabic (Indian) check digits using spatial Gabor Filters”. In GCC Conference Exhibition, IEEE, pp: 1-5.

[22] Ofer Matan, Henry S. Baird, Jane Bromley, Christopher J. C. Burges, John S.Denker, Lawrence D. Jackel, Yann Le Cun, Edwin P. D. Pednault, William D.Satterfield, Charles E. Stenard, and Timothy J. Thompson. (1992), "Reading handwritten digits: A Zip code recognition system". Computer, Vol.25, No.7, pp:59-63.

[23] David Menoti, Dibio Leandro Borges, Jacques Facon, and Alceu de Souza Britto, Jr. (2003), "Segmentation of postal envelopes for address block location: an approach based on feature selection in wavelet space". In Proceedings of the 7th International Conference on Document Analysis and Recognition, Vol.2, pp: 699.

[24] A.S.M.Mahbub Morshed, Md.Shahidul Islam, Md.Abul Faisal, Md.Abdus Sattar, and Mitsuru Ishizuka. (2007), "Automatic sorting of mails by recognizing handwritten postal codes using neural network architectures”. The Pennsylvania State University.

[25] Umapada Pal, Rami Kumar Roy, Kaushik Roy, and Fumitaka Kimura. (2009), "Indian multi-script full pin-code string recognition for postal automation". In Proceedings of the 10th International Conference on Document Analysis and Recognition, pp: 456-460.

[26] Pervez and C.Y. Suen. (1986), "Computer recognition of totally unconstrained handwritten Zip codes". International Journal of Pattern Recognition and Artificial Intelligence.

[27] M. Pfister, S. Behnke, and R. Rojas. (2000), "Recognition of handwritten Zip codes in a real world non-standard letter sorting system". Applied Intelligence.

[28] K. Roy, S. Vajda, U. Pal, and B. B. Chaudhuri. (2004), “ A system towards Indian postal automation". In Proceedings of the Ninth International Workshop on Frontiers in Handwriting Recognition, pp: 580-585.

[29] Y. Saifullah and M.T. Manry. (1993), "Classification-based segmentation of Zip codes". IEEE Transactions on Systems, Man and Cybernetics,Vol.23, No.5, pp:1437-1443.

[30] C.L. Scofield, L. Kenton, and J.C. Chang. (1991), "Multiple neural net architectures for character recognition", In Compcon. Spring. Digest of Papers, pp: 487-491.

[31] Prasun Sinha. (1997), "Cursive Script Postal Address Recognition”. PhD thesis, Michigan State University, East Lansing, US.

[32] Kumar.K. Siva and Devi.D Uma. (2012), "Handwritten Zip code classification using artificial neural networks", International Journal of Engineering Research Technology, Vol.1, No.6.

[33] N. W. Strathy and C. Y. Suen. (1995), "A new system for reading handwritten Zip codes", In Proceedings of the 3rd International Conference on Document Analysis and Recognition, Vol.1, pp: 74.

[34] Asthana Stuti, Farha Haneef and R.K Bhujade. (2011), "Handwritten multi-script numeral recognition using artificial neural networks", International Journal of Soft Computing and Engineering, Vol.1, No.1.

[35] Arun K.S.Jerin Thomas. (2011), “An automated mail sorter system using SVM classifier",International Journal of Computer Applications.

[36] S. Vajda, K. Roy, U. Pal, B. B. Chaudhuri, and A. Belaid. (2009), "Automation of Indian postal documents written in Bangla and English". International Journal of Pattern Recognition and Artificial Intelligence, Vol.23, No.8, pp:1599-1632.

[37] C. M. Velu and Vivekanandan.P. (2010), "Automatic letter sorting for Indian postal address recognition system based on pin codes", Journal of internet and information system,Vol.1, No.6, pp: 15 .

[38] XianWang, Venu Govindaraju, and Sargur Srihari. (1999), "Multi-experts for touching digit string recognition". In Proceedings of the 5th International Conference on Document Analysis and Recognition, pp: 800. 
Signal \& Image Processing : An International Journal (SIPIJ) Vol.4, No.5, October 2013

[39] Yi-Kai Chen Jhing-FaWang. (2001), "Locating the destination address block on images of complex mail pieces", Journal of the Chinese Institute of Engineers.

[40] Ralph Wolf and John C. Platt. (1994), "Postal address block location using a convolutional locator network", Advances in neural information processing system,Vol.6,pp:745-752.

[41] Junliang Xue, Xiaoqing Ding, Changsong Liu, Rui Zhang, and Weiwei Qian. (2001), "Location and interpretation of destination addresses on handwritten Chinese envelopes", Pattern Recognition. Letters, Vol.22, No.6-7, pp:639-656.

[42] H.T Yonh, K.Marzuki, T.K.Kok and Y.Rubyiah. (1997), "Hand-written post code recognition by Fuzzy Artmap neural network". In Proceedings of the Confederation of Scientific and Technological Association.

[43] Bin Yu, A.K. Jain, and M. Mohiuddin. (1997), "Address block location on complex mail pieces". In Proceedings of the 4th International Conference on Document Analysis and Recognition, Vol. 2, pp: 897-901.

\section{AUTHORS}

Dr.R.Radha, aged 44, working as assistant Professor in Shrimathi Devkunvar Nanalal Bhatt Vaishnav College for Women, Chromepet, Chennai, Tamil Nadu, India. She has 20 years of teaching experience. She did her research in Fuzzy Based Data Mining For Effective Decision Support In Bio-Medical Applications. Her research interest is in bio informatics and image processing. She has published 15 papers.

R.R.Aparna a research scholar in Madras university. Her research interest includes Image processing and Artificial Neural networks. She has published 2 papers.

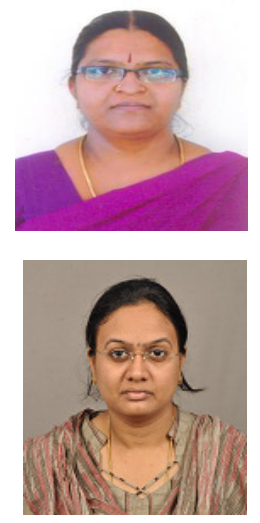

